cardiologist, a pathologist, a head of laboratory, a radiologist, a physician, an anaesthetist and a specialist in physical medicine. Furthermore, there are outside consultants (ear, nose and throat specialist, gynaecologist, eye specialist) who are called in whenever necessary.

The medical staff is assisted by specialised auxiliary personnel, such as the physiotherapists who are trained for three years at a school run by I.N.A.I.L. itself. They attend to all the physiotherapeutic activities both in the wards and in the gymnasium. They are aided by assistant physiotherapists who are trained at the Spinal Centre itself.

The ordinary day-to-day tasks of the wards are carried out by professional nurses trained in courses approved by the State; these are aided by subaltern staff who carry out the less-skilled duties. The ideal proportion of subaltern staff to patients is about $\mathrm{I}: \mathrm{I}$.

The Centre is completed by an orthopaedic workshop where calipers are made to measure for every paraplegic trained to walk. Another workshop sees to the maintenance and repair of all the structures of the Centre. This workshop has a special department for the repair of wheelchairs.

The Villa Marina Spinal Injuries Centre has nowadays a capacity of I Io beds with an average turnover of about 200 paraplegics a year. In the Io years since its foundation, more than 1700 paraplegics and tetraplegics have been hospitalised. The present staff is slightly superior in numbers to the actual needs represented by the present number of inmates. This is due to the fact that a certain number of apprentices are at present being trained in view of a new Spinal Centre which will be built on an area of 80,000 square metres, with a built-up area of 2 I,000 square metres, a total cubature of 108,000 cubic metres and a capacity of more than 300 beds. This Centre should meet the needs of the present and of the immediate future and should also allow for short periods of hospitalisation for the check-ups of former patients and the treatment of relapses of all the paraplegics who come under the responsibility of I.N.A.I.L.

\title{
ISTITUTO FISIOTERAPICO E DI REEDUCAZIONE MOTORIA SELVAPIANA DEL CIRCEO-SABAUDIA, ITALY
}

\author{
By Dr. G. Pedacchia
}

ThE Institute of Physiotherapy and Motor Re-education was founded in 1959 and is run along the lines suggested by Professor Antonio Maglio, director of the I.N.A.I.L. Centre for the Treatment of Paraplegics at Ostia, Lido, which is considered as the pilot Centre in Italy. The Institute is equipped and acts as a centre for paraplegics; at present it has a capacity of roo beds. At the beginning there were only 40 beds, which were increased gradually as follows: I960-6I, 50 beds; I962-63, 70 beds; I964, 90 beds; until, in 1965, the present number of Ioo beds was reached.

Apart from patients suffering from traumatic or viral paraplegia or tetraplegia, also patients with multiple sclerosis, Parkinson's disease or sequelae of cerebral vascular lesions needing treatment and motor re-education are admitted. 
The Institute is situated in one of the most favourable positions of the whole district. The building is placed on the fringes of Selvapiana, at the foot of mount Circeo on the shores of Lake Paola. It is surrounded by a park of 22,000 square metres with paved lanes of varying gradients. The distance from the sea is one kilometre. The climate is cool in summer and mild in winter, owing to the favourable coefficients of mountain, lake and sea and ensures a pleasant, restful and healthy environment for the residents of the Centre. The total surface area, including the building used as lodgings for the staff, is 5000 square metres. Almost all the rooms are double rooms; there are only three larger wards with seven, five and six beds respectively. The Institute is equipped with all modern means of clinical examination, treatment and physiotherapy, including such as basket ball, archery, field events, table tennis and bowling. There is also a heliport in the neighbourhood of the Institute.

The staff comprises the following: medical director, I; administrative staff, 4; consultants and specialists in the different branches (orthopaedics, neurology, urology, oculistics, dentistry), 5; anaesthesiologist, I; medical heads of departments, 3; director of the physio-kinesitherapy department, I; male and female therapists, I2; hospital attendants and male nurses, I6; ward supervisers, 3; secretariat, 2; steward's office, I; orthopaedic technicians for making calipers and prostheses, 2; personnel in charge of various tasks of assistance and services, 32.

Altogether, from I January I959 to 3I December I966, 934 patients have been hospitalised for an average duration of seven and a half months.

The average daily attendance is at present about 95 to roo. About half this number come from the I.N.A.I.L. Centre for Paraplegics at Ostia, Lido; they continue the treatment and rehabilitation courses started at Ostia, Lido, and are well under way when they come to our Centre. The other half usually come from hospitals and social assistance or welfare organisations and as a rule have not had any previous rehabilitation treatment.

In the following there is some statistical data concerning our activity and the results obtained from 1959 to the end of I966:

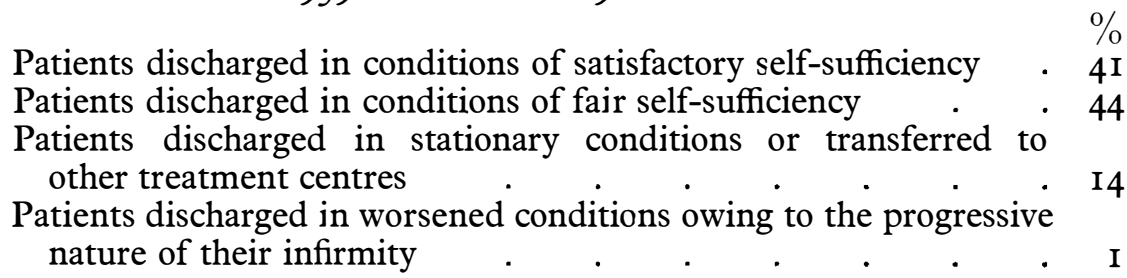

\section{SUMMARY}

A short report illustrating the organisation and activity of the Institute of Physiotherapy and Motor Rehabilitation at Selvapiana del Circeo is given.

After describing the lovely position and architectural conditions of the Institute, the author describes the medical and physiotherapeutic equipment available for the daily activity in the medical and physiotherapeutic fields. The report closes with a few data concerning the total number of patients admitted from 1959 to 1966. 